\title{
Research on the factors and countermeasures of psychological poverty of poor students in colleges and universities
}

\author{
Xingshan $\mathrm{Li}^{1,}$, , Xueping $\mathrm{Xu}^{1}$ \\ ${ }^{1}$ Luohe medical college, Luohe, 462000, China \\ aEmail:604141388@qq.com
}

Keywords: Universities, Poor Students, Psychological Poverty, Guide, Deal With

\begin{abstract}
Different manifestations of the psychological poverty of poor students in universities were listed in the paper. The social and psychological factors that cause these manifestations are analyzed.based on summarizing the problems and puts forward how to resolve psychological poverty and poor college students with poor psychological coping strategies.On the basis of summing up the problems,the countermeasures of how to resolve psychological poverty and poor students in Colleges and Universities was puts forward in this paper .
\end{abstract}

\section{Introduction}

With the development of economy and society in China, the investment of education has been further increased. The number of college students has increased year by year, and the number of poor students will increase accordingly. According to incomplete statistics, about $15 \%$ of our country's university college students in the reading belongs to the poor college students. According to the national ministry of education figures, released by the end of last century, the poor students in colleges and universities and obtains respectively $15 \%$ and $12 \%$ of the total number of college students, And according to the China youth daily survey statistics, the proportion of poor students in the national college students now almost 25\%, extraordinarily poor student almost $10 \% \sim 15 \%$. Therefore, our country each year there will be millions poor college students need jobs, they become the vulnerable groups in the university students' employment can not be neglected. Strengthening employment work, guides them to set up the correct choosing profession idea, develop good employment psychology, realize self value of life, has become the important subject of college students' employment work in common colleges and universities[1].

According to the American scholar ingalls definition of psychological poverty, it is relative to the material poverty, refers to people's moral, beliefs, ideals, values, habits, habits, life concept, value orientation, unable to meet the needs of the real life, behind the state of the main social material production mode. The performance of the psychological poverty in many aspects, such as the low degree of education, scientific and cultural knowledge lack; take things as they are, accustomed to the traditional experience; old ideas, conservative; Severe dependence thoughts, initiative; The lack of cultural and entertainment facilities, less spiritual life; Depressed, inferiority and so on. Cultural degree of college students is high, but in their study and life more and more psychological problems, and according to individual differences, external manifestations appeared pluralism and diversity. 


\section{Treat the right face and understanding of poverty and donation}

In the face of various forms of donations, how do poor college students think. In contact with poor students, the author found that most of the poor students on these issues still have a more correct understanding, but some children have more or less there are some psychological problems. From the overall situation, some of the poor students psychology is healthy, the Yang student of our school 2013 medical imaging professional said that I came from the western Henan, the University of three years of tuition and fees for my family is an astronomical figure. But now I have a junior student, in the past three years I also feel that I am very happy, not too embarrassed. But I did not accept any donations, this is because most of our poor students can go through the school loans to solve large sums of money, and then through the work should be supported. But I always feel in the present society, if people give you a donation, let you participate in several activities can be understood. I don't think it will cause much damage to the students, poor children from primary school to high school is actually in the fight against poverty, their psychological endurance and endurance exercise so greatly, it is generally not so fragile. To be able to get donations will greatly reduce the burden on parents, it's nothing for young people to lose face.

\section{Different understanding of poverty and donation}

1). Type of resolute resistance: I will not change the donor with the self esteem

Example 1: I personally think that through the school student loans and some part-time, is able to rely on their own hands to feed their own. I understand that donors are kindness, but it's hard for me to accept. I have seen, there are a number of donors to the school, and then the principal to be donated to the children standing in front of the whole school teachers and students to accept donations, said some words of gratitude, the family is not a glorious thing. So as a last resort, I will not accept any donations.

2). Type of Mental numbness: Relationship between donors and I are just equivalent exchange

Example 2: I began to appreciate those poor students funded, but I found some clients around me like actors, to participate in various activities and on various occasions to express gratitude, I think this is actually a kind of equivalent exchange relationship, the poor students with dignity for tuition, donors with money in exchange for fame, Who does not owe anyone.

3). Type of self abandonment: I waste donations on material pursuits

Example 3: Just enter the university, I saw my classmates have a cell phone, computer, MP3 player, but I still worry about the money I eat every day, very unbalanced mind, I don't want to appear to be inferior, So I would prefer to use my own money in the "packaging" of my wardrobe, the other students to play the game machine, I also soak in the Internet bar all day, playing the level higher than them. They chase girls, I began to invite girls to eat,etc. Rich students can enjoy something, I also have the right to enjoy.

\section{External manifestation of psychological problems}

The psychological problems of students with financial difficulties are mainly reflected in three aspects.

1).Strong sense of inferiority and sense of loss. Economic difficulties make it easy to poor students in learning, living on the self-denial, think that they are vulnerable groups and feel inferior. During the period of school family economic difficulties students has obvious difference with other classmates, they live frugal, learning seriously. But because of the different growth environment, education environment, their knowledge narrow, often have a hard time learning, and most introverted, this let them have a strong sense of loss, a hit prone to sense of inferiority. 
2). Sensitive interpersonal and loneliness. Family financial difficulties students is very sensitive to interpersonal relationships in mental health status, Family financial difficulties make them reluctant to participate in collective activities and join student organizations, they are often self closed, narrow contact.

3). Confused career mentality and fear. With the increasingly fierce competition in society, one of the most important issues facing the family economic difficulties students need is employment, not only to consider the development of their own in the choice of occupation and life planning, but also think of family economic problems, which brings the pressure of reality to them. In addition, some students have a one-sided understanding of society and are dissatisfied with the society, which further aggravates their psychological burden.

Long term inferiority, depression will make the heart of the poor college students is very fragile, sensitive, The financial distress is that they do not want to mention, afraid of the mercy of the students. For the need of self-protection, paranoid about everything, careless talking and laughing, other students in their sounds may be laughed at, the thing that has nothing to do with themselves, they will think is classmates talk behind your back. Both for their own a lot of unnecessary trouble, and make them more vulnerable to setbacks, which produce hostility and even hostile to others, cause interpersonal tension. At the same time, they usually do not want to let others know their difficulties, it is rather hard for their own, not to help.

The survey of our school was found that $56 \%$ of the poor students which attitude is grateful to help from other students take the initiative, but is unwilling to accept. $31 \%$ of the poor students unwilling to accept the free sponsorship,the reason is that they will be looked down upon by others, can produce bad influence to yourself.

Some medical poor college students due to the economic poverty and derive a series of psychological poverty problem, which directly affect the quality of employment. According to the survey, some medical poor college students mental poverty has serious inferiority and excessive self-esteem, confident and self depression polarization, eager to exchange and self sealing characteristics of conflicting, therefore, strengthen the humanistic care must be taken to build three-dimensional psychological assistance system. Pay attention to environmental education, constructs the overall psychological environment in psychological poverty alleviation measures such as optimizing system lead to their psychological health, improve the quality of employment[2].

\section{Coping strategies of College Students' psychological poverty}

In the job market, there is a lack of communication between employers and poor college students lack, which lead to poor college students slow in the employment process. First of all, according to the characteristics of the company's production and operation personnel to determine the type of talent needed to compare their employment of poor college students and their employment of non poor students. The poor college students did not analyze the objective facts, can not grasp the needs of enterprises . Second, compared with ordinary college students, the idea of poor college students is relatively backward, the lack of effective employment information all the time, the lack of the first to through the network to understand the current employment information and social dynamics [3].

\subsection{Consciousness of accept and pursue equality}

Family wealth of the impact of the psychological impact is relatively large, but on the one hand we must learn to accept, accept different, accept the difference, and can not take rejection and conflict of emotions. on the other hand should have the consciousness of pursuing equality, you 
know, different family background's child strengths and to raise their own, to avoid its short, get along well with teachers and classmates.

\subsection{Giving up can only make you lose more opportunities}

The school has done a survey and found that the addicted to the game of children, the proportion is basically the same of poor children or rich children. This illustrates a problem that many poor children have lost their way in seeking psychological balance. There are some of the children, who chose to escape on the problems such as employment issues because of psychological , but it can only make you lose more opportunities.

\subsection{Psychological counseling, alleviate employment pressure}

Schools to explain to the students, in order to do the work of college graduates, the state, the local government has introduced a series of policies to promote employment, National and central leaders have repeatedly reiterated that the expansion of employment as an economic and social and economic restructuring of the important objectives, improve the employment policy, increase financial investment, and clearly pointed out that in particular, to do the difficulties of employment, college graduates employment jobs. Western governments at all levels should make full use of the national college students employment policy, such as college students volunteer service western plan,three support plan,rural teachers ad hoc job plan and college graduates service rural, service community and a series of employment measures, encourage more poor college graduates to participate in three-pronged or western plan activities[4].

\subsection{Strengthen the employment guidance, to support the poor students employment}

(1)Colleges and universities should pay attention to the employment guidance of poor college students, for the poor students to create a good job conditions. Actively set up employment guidance courses, additional poor students employment guidance topics, to guide poor students to prepare the body and mind, take the initiative to face employment.

(2)In order to solve the problem of poor students' employment psychology, strengthen the knowledge education of poor students' employment, and strengthen the internal motivation. Establish a first employment, after career employment concept, to encourage them to expand their employment ideas, the courage to the country most in need of the place, to the west, frontier and grassroots to display their talent, meritorious deeds.

(3) Implementation of the poor students employment psychological assistance program, giving them more humanistic care, to improve the psychological quality of, the improvement of personal ability to provide advice and help, to feel successful experience,while strengthening the employment guidance for poor students.

\subsection{Guide poor students to do good career planning.}

Use of professional teachers resources, through the scientific evaluation system, for poor students to build a suitable career planning, guiding their targeted for jobs and career[5]. 


\section{People are poor, self-reliance will still dress decent, laugh on the world, never exposed poor phase.}

Material poverty is not terrible, terrible is psychological poverty. Poverty is often associated with the decline of people, Poverty stifles ambition, If psychological poverty, rich will become poor, if psychological rich, poor can also be rich. Material poverty coupled with despair, will soon destroy a person's body, self-confidence and self-reliance, although the temporary material is poor, but the good days will soon come. According to their own professional and personal advantages, play a subjective initiative, step by step employment and Entrepreneurship.

\section{Acknowledgement}

In this paper, the research was sponsored by the College Graduates Employment Entrepreneurship Research project in Henan Province In 2016 (Project No. YB2016110), Henan Soft Science Research project(Project No. 172400410517).

\section{Reference}

[1] Xiao Q F. Problems and countermeasures of poor college students' employment. Education Exploration, 8, 2010: $142-143$.

[2] Xu X P. On the Countermeasures of psychological poverty alleviation for Medical College Students.Modern distance education of Chinese Medicine,1,2016: 30-32

[3] Hu W W. The employment problem of poor students in colleges and universities based on game theory. Journal of Taiyuan City Vocational College,11,2015:49-50

[4] Mo Y X. On the employment difficulties of poor college students in Western China and the Countermeasures. Education Exploration,12,2013:140-141.

[5] Wu M H, Jiang J Y. The performance and Countermeasures of College Students' psychological poverty in the new period. Labor security world,3,2015:14-15. 